Discussion Paper No. 11-050

\title{
Implications of Inequality Aversion for International Climate Policy
}

Carsten Vogt and Bodo Sturm

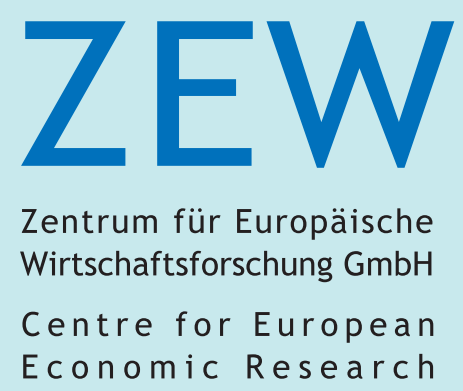


Discussion Paper No. 11-050

\title{
Implications of Inequality Aversion for International Climate Policy
}

\author{
Carsten Vogt and Bodo Sturm
}

Download this ZEW Discussion Paper from our ftp server:

http://ftp.zew.de/pub/zew-docs/dp/dp11050.pdf

Die Discussion Papers dienen einer möglichst schnellen Verbreitung von neueren Forschungsarbeiten des ZEW. Die Beiträge liegen in alleiniger Verantwortung der Autoren und stellen nicht notwendigerweise die Meinung des ZEW dar.

Discussion Papers are intended to make results of ZEW research promptly available to other economists in order to encourage discussion and suggestions for revisions. The authors are solely responsible for the contents which do not necessarily represent the opinion of the ZEW. 


\section{Non-Technical Summary}

Any solution to the problem of voluntary cooperation in international climate policy does not only have to overcome the notorious free rider incentives, but also has to comply with the notions of "equity" and "justice". Inequality aversion, i.e. the disutility of having a higher or lower payoff than others, is one important concept in this area of other-regarding preferences.

In this paper, we analyse the implications of inequality aversion for international climate policy. For this purpose, we extend the Fehr and Schmidt (1999) model of inequality aversion to the context of full heterogeneity, i.e. players in our public good model are allowed to differ with respect to their initial endowments, their degrees of inequality aversion and to their marginal benefits and costs of contributions to the public good. Hence, the model developed in this paper captures all essential aspects of real world international climate policy. There, heterogeneous countries face the opportunity to contribute to the production of the global public good climate protection.

The purpose of this paper is two-fold: Firstly, we derive simple analytical conditions that allow us to identify the circumstances under which perfectly heterogeneous countries are willing to contribute to the public good climate protection. Secondly, we check whether these conditions hold for important negotiating parties in the real world, e.g. China, the EU, Russia and the US. The main theoretical result is that a country's benefit has to exceed some critical value as a necessary condition for contributing to the global public good climate protection, whereby this critical value depends on a country's degree of inequality aversion, its position in the payoff ranking, its costs of contributing and other countries' benefits. It is exactly this condition that is used for the empirical test. We employ data from Nordhaus' RICE, a regionalised impact assessment model, to estimate empirical benefits and costs of climate protection for different regions. The data input for the degree of inequality aversion is taken from the experimental economics literature. We then show that for major countries involved in international climate policy such as China, the US and Russia, the necessary condition for contributing is violated - at least for the time horizon until 2055. Thus, although inequality aversion theoretically enhances the prospects for voluntary cooperation in providing public goods, it is advisable not to overestimate its potential for overcoming cooperation problems in real world climate policy. 


\section{Das Wichtigste in Kürze}

Eine Lösung des Kooperationsproblems in der globalen Klimapolitik erfordert neben einer deutlichen Senkung der Treibhausgasemissionen eine von den Beteiligten als „fair“ empfundene Aufteilung der mit der Emissionsreduktion verbundenen Lasten. Ein wichtiges Konzept zur Abbildung von Fairnesspräferenzen ist Ungleichheitsaversion, d.h. der Nutzenverlust, der dadurch entsteht, dass man eine höhere oder niedrigere Auszahlung als andere Akteure hat.

In diesem Papier untersuchen wir die Auswirkungen von Ungleichheitsaversion auf die internationale Klimapolitik. Hierzu erweitern wir das Ungleichheitsaversion-Modell von Fehr und Schmidt (1999) auf den Fall vollständiger Heterogenität. Akteure in dem untersuchten Öffentliches-Gut-Spiel unterscheiden sich hinsichtlich ihrer Anfangsausstattung, dem Ausmaß an Ungleichheitsaversion und den Nutzen und Kosten des Beitrags zum öffentlichen Gut. Damit bildet das untersuchte Modell alle Aspekte der realen Klimapolitik ab. Auch hier haben heterogene Akteure (Länder) die Möglichkeit, Beiträge zur Erstellung eines öffentlichen Guts (Klimaschutz) zu leisten.

Im Papier wird zunächst theoretisch gezeigt, welche kritische Bedingung erfüllt sein muss, damit heterogene Akteure bereit sind, zum öffentlichen Gut Klimaschutz beizutragen. Im Anschluss wird überprüft, ob die hergeleitete kritische Bedingung für wichtige Akteure in der realen Klimapolitik, z.B. China, EU, Russland und USA, erfüllt ist. Als kritische Bedingung kann hergeleitet werden, dass der Nutzen aus dem Beitrag zum Klimaschutz für ein Land einen kritischen Wert übersteigen muss. Dieser kritische Wert ist abhängig von der Ungleichheitsaversion des Landes, seiner Position in der Rangordnung der Pro-KopfEinkommen, seinen Kosten des Beitrags und dem Nutzen aller anderen Länder. Diese kritische Bedingung wird dann einem empirischen Test unterzogen. Hierzu nutzen wir Daten des regionalisierten Klima-Ökonomie-Modells RICE von William Nordhaus. RICE liefert regionalisierte Nutzen und Kosten für unterschiedliche Klimaschutzszenarien. Der Dateninput für Ungleichheitsaversion stammt aus der experimentellen Wirtschaftsforschung. Wir können als zentrales Resultat zeigen, dass für wichtige Verhandlungsparteien in der internationalen Klimapolitik wie China, USA und Russland die kritische Bedingung für den Beitrag zum öffentlichen Gut Klimaschutz nicht erfüllt ist - zumindest bis 2055. Das bedeutet: Obwohl Ungleichheitsaversion theoretisch die Kooperationschancen bei der Bereitstellung öffentlicher Güter erhöht, ist in der realen Klimapolitik nicht damit zu rechnen, dass sich die Aussichten auf Kooperation durch die Berücksichtigung von Ungleichheitsaversion deutlich verbessern. 


\title{
Implications of Inequality Aversion
}

\section{for International Climate Policy}

\author{
Carsten Vogt ${ }^{\mathrm{a}}$ and Bodo Sturm ${ }^{\mathrm{b}, \mathrm{c}}$ \\ ${ }^{a}$ Department of Business Administration, Bochum University of Applied Sciences \\ ${ }^{b}$ Department of Business Administration, Leipzig University of Applied Sciences \\ ${ }^{\mathrm{c}}$ Centre for European Economic Research (ZEW), Mannheim
}

\author{
E-mail: \\ carsten.vogt@hs-bochum.de, \\ bodo.sturm@wiwi.htwk-leipzig.de
}

\begin{abstract}
In this paper, we extend the Fehr and Schmidt model of inequality aversion to a situation where the players differ with respect to their benefits and costs from contributions to a non-linear public good. A necessary condition for contributing to the public good is that the players' benefit exceeds some critical value. Using data from the impact assessment model RICE and estimates for inequality aversion from the experimental literature, we show that this condition fails to hold for major countries involved in international climate policy.
\end{abstract}

JEL classification: C72, D63, H41, Q54

Keywords: Climate policy, public good game, inequality aversion, voluntary cooperation

Acknowledgements: The authors would like to thank Andreas Lange for helpful comments. 


\section{Introduction}

Any solution to the problem of voluntary cooperation in international climate policy does not only have to overcome the notorious free rider incentives, but also has to comply with notions of "equity" and "justice" (e.g. Posner and Weisbach 2010). Several important parties involved in the climate talks, like the G77/China, strive for an "equitable burden sharing". Within the EU, notions of equity also played a role when the internal burden sharing for EU members was fixed after the adoption of the overall EU reduction target of $8 \%$ under the Kyoto Protocol. Within the academic sphere, studies like Lange et al. (2007) provide empirical support for the idea that equity is an important issue in the negotiation arena of climate policy. Furthermore, negotiators may be truly motivated by some notion of equity: Dannenberg et al. (2010) find empirical support for the hypothesis that climate negotiators show relatively high degrees of inequality aversion as a prominent example of equity preferences. Moreover, broad evidence from experimental economics suggests that a significant fraction of subjects is to some extent guided by equity concerns such as inequality aversion. Subjects reject high amounts of money in the ultimatum game (Güth et al. 1982, Oosterbeek et al. 2003), and they make positive contributions in the dictator game (Kahneman et al. 1986, Engel 2010). Fischbacher and Gächter (2010) provide strong empirical evidence for the explanatory power of inequality aversion. Their study demonstrates that the typical observation of declining contributions in repeated public good games can easily be explained since players gain knowledge of their co-players' displayed inequality aversion in previous rounds, on which future beliefs can be based.

Inequality aversion has been introduced as an analytical concept in economics by Fehr and Schmidt (1999, hereafter called F\&S). In their highly influential paper, they assume that actors derive disutility from unequal outcomes. Thereby, players may show an aversion to both disadvantageous and advantageous inequality. The interesting implication of this idea is that it provides an easy and elegant explanation of why players should voluntarily cooperate in a social dilemma. The reason is quite simple: If a player is sufficiently averse to advantageous inequality, he will simply abstain from exploiting the free rider opportunity. The cooperation-enhancing effect of this type of preferences has already been shown for a linear public good game by F\&S themselves. Lange and Vogt (2003) show that this effect

\footnotetext{
${ }^{1}$ However, these observations may be ambiguous. As Lange et al. (2010) point out, the use of equity criteria in climate negotiations may be motivated by pure economic self-interest. I.e. the preference for some equity criterion may to a large extent be explained with considerations of minimising the costs of implementing treaty obligations. In this paper, we take the idea of inequality aversion seriously, i.e. we do not assume that it can be perfectly explained by purely strategic considerations that influence the bargaining outcome.
} 
also appears in a more complicated two-stage $N$-player coalition game. Their analysis is, however, restricted to symmetric countries. Lange (2006) points out that more severe intricacies in sustaining cooperative outcomes are the consequence if the players are allowed to be heterogeneous.

In this paper, we extend the F\&S model of inequality aversion to the context of full heterogeneity, i.e. players in our non-linear public good model are allowed to differ with respect to their initial endowments, their degrees of inequality aversion and - this is new - to their marginal benefits and costs of contributions to the public good. Hence, the model developed in this paper captures all essential aspects of real world international climate policy. There, countries face the opportunity to contribute to the production of the global public good climate protection. However, countries in the real world are obviously highly diverse with respect to their economic wealth as well as their benefits and costs of climate protection. Thus, a specific degree of inequality aversion may have different effects on the countries' incentives to contribute.

The purpose of this paper is two-fold: Firstly, we derive simple analytical conditions that allow us to identify the circumstances under which perfectly heterogeneous countries are willing to contribute to the public good climate protection. Secondly, we check whether these conditions hold for important negotiating parties in the real world, e.g. the US, the EU, Russia and China. We are primarily concerned with the time horizon until 2055 - since this time period dominates the current climate negotiations. The main theoretical result is that a country's benefit has to exceed some critical value as a necessary condition for contributing to the global public good climate protection, whereby this critical value depends on a country's degree of inequality aversion, its position in the payoff ranking, its costs of contributing and other countries' benefits. It is exactly this condition which is used for the empirical test. We employ data from Nordhaus' RICE model, a regionalised impact assessment model, to estimate empirical benefits and costs of climate protection for different regions. The data input for the degree of inequality aversion is taken from the experimental economics literature. We then show that for major countries involved in international climate policy, the necessary condition for contributing is violated. Thus, although inequality aversion theoretically enhances the prospects for voluntary cooperation in providing public goods drastically, it is advisable not to overestimate its potential for overcoming cooperation problems in real world climate policy. 
This paper is structured as follows. In Section 2, we provide the non-linear public good model with heterogeneous players and derive the necessary condition for contributing to the public good. In Section 3, we investigate the prospects for voluntary cooperation in climate policy using the derived theoretical framework and empirically estimated values for inequality aversion, and benefits and costs from climate policy. In Section 4, we discuss the results and draw a conclusion.

\section{The model}

In this paper, we deal with a non-linear public good model in order to investigate the prospects for an international climate agreement. In this model, actors are endowed with some initial allocation which can be kept for private consumption or be devoted to the production of some public good. Let there be $i=1, \ldots, N$ players and consider an arbitrary player $j$. Each player is endowed with some amount of private good $z_{j}$. Let $q_{j}=z_{j}-x_{j}$ denote the amount of private good that player $j$ devotes to the production of the public good $y$. Hence, $x_{j}$ is the amount of the initial endowment that player $j$ keeps for private consumption. The public good $y$ is produced according to some non-linear production function $y=g(Q)$ where $Q=\sum_{j=1}^{N} q_{j}$. The players' payoffs consist of the amounts of the private and the public good they consume, i.e. $\pi_{j}\left(x_{j}, y\right)=x_{j} p_{j}+a_{j} y$. The parameter $p_{j}$ denotes the marginal opportunity costs for the investment in the public good, i.e. the loss of private consumption if player $j$ decides to devote one more unit of endowment to the public good $y$. The parameter $a_{j}$ measures the productivity of player $j$ 's individual contribution and the term $a_{j} g^{\prime}$ is $j$ 's benefit from investing one more unit of endowment to the public good. With respect to parameters $a_{j}$ and $p_{j}$ and the production function, we assume $\sum_{j} a_{j} g^{\prime}>p_{j}>a_{j} g^{\prime}$, where $\sum_{j} a_{j} g^{\prime}$ measures the marginal social benefit from an investment to the public good by player $j$. The payoff for player $j$ then results as

$$
\pi_{j}=\left(z_{j}-q_{j}\right) p_{j}+a_{j} g(Q)
$$

Note that, if $j$ decides to invest one unit of endowment to the public good, he creates a positive externality: All other players receive an additional payoff according to their marginal benefit. Players who act economically rational and selfish will not take these externalities into 
account. Since the marginal social benefit of contributing $\sum_{j} a_{j} g^{\prime}$ exceeds the marginal costs of costs of contributing $p_{j}$, which exceed the private marginal benefit of contributing $a_{j} g^{\prime}$, the amount of the public good provided collectively in Nash equilibrium $\left(q_{j}^{\text {Nash }}=0\right)$ falls short of the efficient level $\left(q_{j}^{e f f}=z_{j}\right)$.

However, the result sketched out above only holds for standard preferences. F\&S introduce the idea that actors may be averse to inequality. ${ }^{2}$ They formalise the idea of inequality aversion by introducing the following utility for player $j$, given the payoffs for all other players $i$ :

$U_{j}\left(\pi_{j}, \pi_{i}\right)=\pi_{j}-\frac{\alpha_{j}}{N-1} \sum_{i \neq j}^{N} \max \left\{\pi_{i}-\pi_{j}, 0\right\}-\frac{\beta_{j}}{N-1} \sum_{i \neq j}^{N} \max \left\{\pi_{j}-\pi_{i}, 0\right\}$

For $\alpha_{j}, \beta_{j}>0$, (2) implies that player $j$ derives disutility from inequality. The second term represents disutility from disadvantageous inequality (in case of $\pi_{i}>\pi_{j}$ ), while the third term reflects disutility from advantageous inequality (in case of $\pi_{j}>\pi_{i}$ ). With respect to parameter $\beta_{j}, \mathrm{~F} \& \mathrm{~S}$ assume in addition $\beta_{j}<1 .^{3}$

Now let us apply this utility function to the non-linear public good game. In this paper, we allow for full heterogeneity of all players, i.e. the players differ with respect to their degrees of inequality aversion, they may face different initial allocations and, most importantly, the players are characterised by varying benefits and costs of contributions to the public good. Let us consider an arbitrary player $j$ within the payoff order generated by the vector of initial endowments and the vector of contributions by all players $i=1, \ldots, N$. Player $j$ 's utility is generally given by

$U_{j}\left(\pi_{j}, \pi_{h}, \pi_{l}\right)=\pi_{j}-\frac{\alpha_{j}}{N-1}\left[\sum_{h: \pi_{h}>\pi_{j}}\left(\pi_{h}-\pi_{j}\right)\right]-\frac{\beta_{j}}{N-1}\left[\sum_{l: \pi_{j}>\pi_{l}}\left(\pi_{j}-\pi_{l}\right)\right]$

\footnotetext{
${ }^{2}$ Bolton and Ockenfels (2000) also propose an influential model of inequality aversion. Our choice of F\&S' model is simply motivated by its greater mathematical simplicity.

${ }^{3}$ The justification for this restriction is quite plausible. For simplification, assume a two-player case and that one player has a higher payoff than the other. Allowing $\beta=1$ would mean that the first player is prepared to throw one euro away in order to reduce his advantage. $\beta>1$ implies that he is even willing to throw away more than one euro.
} 
Thereby, $h$ denotes players who rank above player $j$ in the payoff hierarchy and $l$ denotes those players who rank below. Hence, $\frac{\alpha_{j}}{N-1}\left[\sum_{h: \pi_{h}>\pi_{j}}\left(\pi_{h}-\pi_{j}\right)\right]$ is the total disadvantageous inequality weighted by $\alpha_{j}$ and normalised by $N-1$, while $\frac{\beta_{j}}{N-1}\left[\sum_{l: \pi_{j}>\pi_{l}}\left(\pi_{j}-\pi_{l}\right)\right]$ is the total advantageous inequality weighted by $\beta_{j}$ and normalised by $N-1$. By inserting payoffs according to (1) and (3), we can derive player $j$ 's utility as

$$
\begin{aligned}
U_{j}\left(q_{j}, q_{h}, q_{l}\right)= & \left(z_{j}-q_{j}\right) p_{j}+a_{j} g(Q)-\frac{\alpha_{j}}{N-1}\left[\sum_{h}\left(\left(\left(z_{h}-q_{h}\right) p_{h}+a_{h} g(Q)\right)-\left(\left(z_{j}-q_{j}\right) p_{j}+a_{j} g(Q)\right)\right)\right] \\
& -\frac{\beta_{j}}{N-1}\left[\sum_{l}\left(\left(\left(z_{j}-q_{j}\right) p_{j}+a_{j} g(Q)\right)-\left(\left(z_{l}-q_{l}\right) p_{l}+a_{l} g(Q)\right)\right)\right]= \\
& \left(z_{j}-q_{j}\right) p_{j}+a_{j} g(Q)-\frac{\alpha_{j}}{N-1}\left[\sum_{h}\left(\left(z_{h}-q_{h}\right) p_{h}-\left(z_{j}-q_{j}\right) p_{j}\right)\right] \\
& -\frac{\beta_{j}}{N-1}\left[\sum_{l}\left(\left(z_{j}-q_{j}\right) p_{j}-\left(z_{l}-q_{l}\right) p_{l}\right)\right] \\
& -\frac{\alpha_{j}}{N-1} g(Q) \sum_{h}\left(a_{h}-a_{j}\right)-\frac{\beta_{j}}{N-1} g(Q) \sum_{l}\left(a_{j}-a_{l}\right)
\end{aligned}
$$

We are interested in the condition under which player $j$ decides to contribute voluntarily to the production of the public good. To make contributing worthwhile, it must not pay off to deviate from any given positive contribution level $q_{j}>0$. In particular, it must not pay off to contribute less than $q_{j}$. Thus, let us consider an arbitrary deviation $\Delta$ below $q_{j}$. The utility in the case where player $j$ chooses to deviate is given as

$$
\begin{aligned}
U_{j}\left(q_{j}-\Delta, q_{h}, q_{l}\right)= & \left(z_{j}-q_{j}+\Delta\right) p_{j}+a_{j} g(Q-\Delta)-\frac{\alpha_{j}}{N-1}\left[\sum_{h}\left(\left(z_{h}-q_{h}\right) p_{h}-\left(z_{j}-q_{j}+\Delta\right) p_{j}\right)\right] \\
& -\frac{\beta_{j}}{N-1}\left[\sum_{l}\left(\left(z_{j}-q_{j}+\Delta\right) p_{j}-\left(z_{l}-q_{l}\right) p_{l}\right)\right] \\
& -\frac{\alpha_{j}}{N-1} g(Q-\Delta) \sum_{h}\left(a_{h}-a_{j}\right)-\frac{\beta_{j}}{N-1} g(Q-\Delta) \sum_{l}\left(a_{j}-a_{l}\right)
\end{aligned}
$$

We use the following approximation for $g(Q-\Delta)$ :

$$
g^{\prime}(Q) \approx \frac{g(Q)-g(Q-\Delta)}{Q-(Q-\Delta)}=\frac{g(Q)-g(Q-\Delta)}{\Delta} \Leftrightarrow g(Q-\Delta)=g(Q)-\Delta g^{\prime}(Q)
$$

The utility from deviating results as follows: 


$$
\begin{aligned}
U_{j}\left(q_{j}-\Delta, q_{h}, q_{l}\right)= & \left(z_{j}-q_{j}+\Delta\right) p_{j}+a_{j}\left(g(Q)-\Delta g^{\prime}(Q)\right) \\
& -\frac{\alpha_{j}}{N-1}\left[\sum_{h}\left(\left(z_{h}-q_{h}\right) p_{h}-\left(z_{j}-q_{j}+\Delta\right) p_{j}\right)\right] \\
& -\frac{\beta_{j}}{N-1}\left[\sum_{l_{l}}\left(\left(z_{j}-q_{j}+\Delta\right) p_{j}-\left(z_{l}-q_{l}\right) p_{l}\right)\right] \\
& -\frac{\alpha_{j}}{N-1}\left(g(Q)-\Delta g^{\prime}(Q)\right) \sum_{h}\left(a_{h}-a_{j}\right) \\
& -\frac{\beta_{j}}{N-1}\left(g(Q)-\Delta g^{\prime}(Q)\right) \sum_{l}\left(a_{j}-a_{l}\right)
\end{aligned}
$$

Now, we have to compare (4) and (6). Clearly, contributing pays off if

$$
\begin{aligned}
& U_{j}\left(q_{j}, q_{h}, q_{l}\right)>U_{j}\left(q_{j}-\Delta, q_{h}, q_{l}\right) \Leftrightarrow \\
& 0>(N-1) \Delta\left(p_{j}-a_{j} g^{\prime}\right)+\alpha_{j} p_{j} h \Delta-\beta_{j} p_{j} l \Delta+\alpha_{j} \Delta g^{\prime} \sum_{h}\left(a_{h}-a_{j}\right)+\beta_{j} g^{\prime} \Delta \sum_{l}\left(a_{j}-a_{l}\right)
\end{aligned}
$$

(7) can be solved for several variables. If we treat $\alpha_{j}, \beta_{j}, p_{j}$ and $a_{j}$ as given parameters, it might be interesting to solve the term for $h$. This allows us to investigate how the position within the payoff hierarchy affects the decision to contribute or not. Recognising that $l \equiv N-h-1$, we get

$$
h<\frac{\left(\beta_{j} \sum_{l} a_{l}-\alpha_{j} \sum_{h} a_{h}\right) g^{\prime}-(N-1)\left(p_{j}-a_{j} g^{\prime}\right)\left(1-\beta_{j}\right)}{\left(p_{j}-a_{j} g^{\prime}\right)\left(\alpha_{j}+\beta_{j}\right)} \equiv h^{c r i t}, \text { if } p_{j}-a_{j} g^{\prime}>0
$$

and

$h>\frac{\left(\beta_{j} \sum_{l} a_{l}-\alpha_{j} \sum_{h} a_{h}\right) g^{\prime}-(N-1)\left(p_{j}-a_{j} g^{\prime}\right)\left(1-\beta_{j}\right)}{\left(p_{j}-a_{j} g^{\prime}\right)\left(\alpha_{j}+\beta_{j}\right)} \equiv h^{c r i t}$, if $p_{j}-a_{j} g^{\prime}<0$

(8) tells us that player $j$ will only choose to contribute if $h$ is sufficiently low, i.e. player $j$ ranks sufficiently high in the payoff hierarchy. However, a second case may also occur: If the marginal benefit exceeds the marginal costs, then player $j$ will contribute only if he ranks sufficiently low. Surprisingly, this case is empirically of particular relevance when we consider a time horizon in climate policy until 2100 . We will come back to this point later. For our purposes, it is interesting to have a closer look at the RHS of (8) and (8'). Consider 
the first case, i.e. $p_{j}-a_{j} g^{\prime}>0$. We are looking for a lower bound of $h^{\text {crit }}$. Clearly, for (8) to hold, the RHS has to be positive. Thus,

$$
h^{c r i t}>0 \Leftrightarrow a_{j} g^{\prime}>p_{j}+\frac{\alpha_{j} \sum_{h} a_{h}-\beta_{j} \sum_{l} a_{l}}{(N-1)\left(1-\beta_{j}\right)} g^{\prime} \equiv b_{j}^{c r i t 1}
$$

(9) is a necessary condition for contributing. It states that player $j$ will choose to contribute to the public good if his marginal benefit from contributing, $a_{j} g^{\prime}$, is high enough, i.e. exceeds the critical marginal benefit $b_{j}^{\text {crit } 1}$. (9) is well suited to easily study how changes in parameter values affect the decision to contribute: An increase in $\alpha_{j}$ makes (9) more demanding $\left(\frac{\partial}{\partial \alpha_{j}} b_{j}^{c r i t 1}>0\right)$, while with increasing $\beta_{j}(9)$ becomes less restrictive. The last conjecture can easily be confirmed by looking at the corresponding partial derivative:

$$
\frac{\partial}{\partial \beta_{j}} b_{j}^{c r i t 1}=\frac{-g^{\prime} \sum_{l} a_{l}\left[(N-1)\left(1-\beta_{j}\right)\right]+(N-1)\left(\alpha_{j} \sum_{h} a_{h}-\beta_{j} \sum_{l} a_{l}\right) g^{\prime}}{\left[(N-1)\left(1-\beta_{j}\right)\right]^{2}} .
$$

Note that $p_{j}>a_{j} g^{\prime}$ implies $\alpha_{j} \sum_{h} a_{h}<\beta_{j} \sum_{l} a_{l}$. Hence, $\frac{\partial}{\partial \beta_{j}} b_{j}^{c r i t 1}<0$.

Consequently, if players are highly averse to advantageous inequality, their incentives to contribute will increase. On the other hand, stronger disadvantageous inequality makes voluntary cooperation in the production of public goods more difficult. Moreover, (9) is also suited to discuss the role of the position within the payoff hierarchy. Obviously, the more players rank above (or below) player $j$ in the payoff hierarchy, the higher (or lower) the value $\sum_{h} a_{h}$ and the more (or less) demanding is (9).

The intuition behind the comparative statics is quite easy: Deviating downward from some positive contribution level leads to a higher absolute payoff for the deviating player. So ceteris paribus, the disadvantageous inequality is reduced. The higher $\alpha_{j}$, the stronger this effect is. On the other hand, deviating creates additional advantageous inequality. Thus, higher values of $\beta_{j}$ make it less worthwhile to deviate.

Now consider the second case, i.e. $p_{j}-a_{j} g^{\prime}<0$. Then, for condition (8') to hold, the RHS must not exceed $N-1$, the corresponding upper bound of $h^{\text {crit }}$. Hence, 
$h^{\text {crit }}<N-1 \Leftrightarrow a_{j} g^{\prime}>p_{j}+\frac{\alpha_{j} \sum_{h} a_{h}-\beta_{j} \sum_{l} a_{l}}{(N-1)\left(1+\alpha_{j}\right)} g^{\prime} \equiv b_{j}^{\text {crit } 2}$

Obviously, the comparative statics run in the same direction as for (9).

\section{Prospects for voluntary cooperation in climate policy}

In this section, we use our model developed in Section 2 to investigate the prospects for voluntary cooperation in international climate policy. It is well known that preferences like the ones proposed by $F \& S$ have the potential to greatly facilitate cooperation in the production of public goods. ${ }^{4}$ For example, Lange and Vogt (2003) show that even the grand coalition of all countries of the world can be stabilised as a Nash equilibrium in a two-stage coalition formation game, if all players are sufficiently averse to advantageous inequality. Yet the question of whether inequality aversion really helps to ease cooperation in practice has to be answered empirically. In this section, we use conditions (9) and (10) in order to investigate whether real world countries have incentives to contribute to the global public good climate protection.

Remember condition (9). It states that - given the values for the aversion parameters $\alpha_{j}$ and $\beta_{j}$ and given a country's position within the payoff hierarchy (i.e. given the values of $\sum_{h} a_{h}$ and $\left.\sum_{l} a_{l}\right)$ - the country's marginal benefit, $a_{j} g^{\prime}$, must exceed the critical value on the RHS of (9), $b_{j}^{\text {crit } 1}$, in order to contribute. Hence, in order to evaluate (9) and (10) empirically, we need values for $\alpha_{j}$ and $\beta_{j}$ as well as for $\sum_{h} a_{h} g^{\prime}$ and $\sum_{l} a_{l} g^{\prime}$.

\subsection{Estimates for inequality aversion}

There are only few studies so far which try to estimate empirical values for $\alpha$ and $\beta$. F\&S themselves use data from Roth (1995) and others and derive the distribution for $\alpha$ and $\beta$ according to the observed behaviour of proposers and responders in the ultimatum game. Parameter $\alpha_{j}$ can be derived directly from the responder's acceptance behaviour. The distribution over $\alpha$ is shown in Table 1. If a proposer does not know the parameter $\alpha_{j}$ of the

\footnotetext{
${ }^{4}$ The use of equity preferences in the context of international negotiations at government level can be justified by simple political economy reasoning: Governments or their delegates in international climate negotiations may be forced to take equity considerations into account if their pivotal voter at home shows corresponding concerns.
} 
responder but believes that the probability distribution over $\alpha$ is the one given in Table 1, then the responder's optimal offer can be derived as a function of his inequality parameter $\beta_{j}$. Given the actual offers in ultimatum games, the distribution of $\beta$ can be computed as depicted in Table $1 . .^{5}$

Table 1: Distribution of Inequality Parameters as Assumed by F\&S

\begin{tabular}{crcc}
\hline \hline \multicolumn{2}{c}{ distribution of $\alpha$ 's } & \multicolumn{2}{c}{ distribution of $\beta$ 's } \\
\hline $0 \leq \alpha<0.5$ & $30 \%$ & $\beta<0.235$ & $30 \%$ \\
$0.5 \leq \alpha<1$ & $30 \%$ & $0.235 \leq \beta<0.5$ & $30 \%$ \\
$1 \leq \alpha<4$ & $30 \%$ & $\beta \geq 0.5$ & $40 \%$ \\
$4 \leq \alpha<\infty$ & $10 \%$ & & \\
\hline \multicolumn{2}{c}{$\alpha_{[0.5]}=0.833$} & \multicolumn{2}{c}{$\beta_{[0.5]}=0.288$} \\
\hline \hline
\end{tabular}

Notes: The median values, $\alpha_{[0.5]}$ and $\beta_{[0.5]}$, are derived by linear approximation according to the intervals F\&S propose (p. 843-844). In their Table III, F\&S assume for both parameters few points in the density with mass. This leads to $\bar{\alpha}=0.85$ and $\bar{\beta}=0.315$. See Section 3.4 for a sensitivity analysis.

We use the distribution shown in Table 1 in order to compute the median by linear approximation of the empirical cumulated density function. This leads to $\alpha_{[0.5]}=0.833$ and $\beta_{[0.5]}=0.288$. We proceed with these values in our analysis and assume that each region has the same degree of inequality aversion. ${ }^{6}$ A sensitivity analysis of our results with respect to the chosen values for $\alpha$ and $\beta$ is given in Section 3.4.

\subsection{Estimates for benefits and costs}

Our estimates for benefits and costs of climate protection are based on the impact assessment model RICE ("regional integrated model of climate and the economy") developed by William Nordhaus (Nordhaus 2010). RICE views climate change in the framework of the economic growth theory. In a standard neoclassical optimal growth model, the society invests in capital goods, thereby reducing the current consumption so as to increase consumption in the future. RICE modifies the growth model to include climate investments. The capital stock of the conventional model is extended to include investments in the environment (natural capital).

\footnotetext{
${ }^{5} \mathrm{~F} \& \mathrm{~S}$ show that the distribution in Table 1 is consistent with the behavior in a broad range of experiments.

${ }_{6}^{6}$ This assumption seems to be warranted since in Dannenberg et al. (2010) the estimated values for F\&S parameters of negotiators in international climate policy do not differ across different regions of the world.
} 
Emissions reductions in the extended model are analogous to capital investments in the mainstream model. That is, concentrations of greenhouse gases (GHGs) are modelled as "negative natural capital" and emissions reductions as lowering the quantity of that negative capital. Emissions reductions lower the current consumption, but, by preventing economically harmful climate change, increase consumption possibilities in the future. The model divides the world into 12 regions. Some are large countries, such as the United States or China; others are large multi-country regions, such as the European Union or Latin America. Each region is assumed to have a well-defined set of preferences, represented by a social welfare function, and to optimise its consumption, GHG policies and investment over time. The social welfare function is increasing in the per capita consumption of each generation, with diminishing marginal utility of consumption. The importance of a generation's per capita consumption depends on its relative size. The relative importance of different generations is measured using a pure rate of time preference, and the curvature of the utility function is given by the elasticity of the marginal utility of consumption. These parameters are calibrated to ensure that the real interest rate in the model is close to the average real interest rate and the average real return on capital in real-world markets. The model contains both a traditional economic sector, like those found in many economic models, and geophysical relationships designed for climate-change modelling.

Based on RICE, several scenarios on future climate policy can be investigated. For our purposes, the scenarios "Baseline" and "Optimal" are relevant. In Baseline, no global climate change policies are adopted, i.e. complete inaction on international climate policies is assumed. In Optimal, climate change policies maximise economic welfare with full participation by all nations starting in 2010 and without climatic constraints. Thus, in this case the most efficient climate-change policies are assumed. Thereby, efficiency involves a balancing of the abatement costs and the benefits of reduced climate damages.

There seems to be some inconsistency between RICE and our public good model. While RICE assumes governments to maximise welfare functions based on neoclassical standard preferences, actors in our model are partly motivated by inequality aversion. Note, however, that we only use RICE to obtain empirical estimates for the benefits and costs.

By considering the Optimal versus the Baseline scenario, we assume a rather optimistic case of climate policy where the difference between national benefits and costs is large. Any more ambitious mitigation policy, e.g. a mitigation policy aiming at the 2-degree target, would necessarily lead to a less favourable benefit-cost ratio (Nordhaus 2008). Thus, by considering 
the Optimal scenario from RICE, we give our critical conditions (9) and (10), respectively, a rather good chance of being fulfilled.

Table 2 shows benefits and abatement costs for the 12 regions in RICE as differences between the Optimal and Baseline scenarios for two different time horizons, one until 2055 and the other until 2100. The benefit values for region $j$ correspond to $a_{j} g^{\prime}$ in our model, since we consider a discrete choice between only two scenarios. Analogously, abatement cost values for region $j$ correspond to $p_{j}$. For example, given a time horizon until 2055, the US has 90.1 bn $\$_{2005}$ of higher benefits and 148.9 bn $\$_{2005}$ of higher abatement costs in Optimal compared to Baseline. This leads to a benefit-cost ratio of 0.61. Since with longer time horizon, benefits from abatement (i.e. reduced damages of climate change) will increase, the corresponding benefit-cost ratio for a time horizon until 2100 is 1.06. For the EU, mitigation benefits are higher (101.4 bn $\left.\$_{2005}\right)$ and the abatement costs are lower $(72.4 \mathrm{bn} \$ 2005)$, leading to a more favourable benefit-cost ratio of 1.40 for the time horizon until 2055.

For the time horizon until 2055, only a few regions will gain a net benefit in full cooperation: the EU, India, Africa, and Latin America. These are the regions that will be significantly hit by an unmitigated climate change in the medium term. On the other hand, major emitting countries such as the US, Russia and China have a benefit-cost ratio that is below one. Given the standard preferences, these regions will lose in full cooperation, since their benefits from mitigation are smaller than their abatement costs. In other words, the fundamental incentives to participate in an international climate agreement are not given.

Table 2: Benefits and Abatement Costs in RICE

\begin{tabular}{|c|c|c|c|c|c|c|c|c|c|c|c|c|}
\hline \multirow[t]{2}{*}{ bn $\$ 2005$} & \multicolumn{12}{|l|}{ Region } \\
\hline & $\mathrm{CHI}$ & US & RUS & JPN & EU & IND & LatA & AFR & MidE & EurA & $\mathrm{OHI}$ & Other \\
\hline \multicolumn{13}{|c|}{ Benefits through } \\
\hline 2055 & 95.1 & 90.1 & 8.9 & 21.4 & 101.4 & 93.6 & 57.4 & 68.9 & 82.6 & 7.0 & 32.0 & 72.0 \\
\hline 2100 & 370.4 & 308.2 & 28.4 & 64.3 & 340.3 & 370.0 & 215.9 & 337.9 & 316.8 & 26.9 & 106.2 & 328.4 \\
\hline \multicolumn{13}{|c|}{ Abatement costs through } \\
\hline 2055 & 302.5 & 148.9 & 43.7 & 22.2 & 72.4 & 83.6 & 52.3 & 35.9 & 95.5 & 27.8 & 44.7 & 80.2 \\
\hline 2100 & 578.9 & 292.0 & 80.7 & 38.6 & 142.3 & 198.6 & 120.0 & 99.6 & 225.8 & 55.5 & 82.3 & 212.8 \\
\hline \multicolumn{13}{|c|}{ Benefit-cost ratio } \\
\hline 2055 & 0.31 & 0.61 & 0.20 & 0.96 & 1.40 & 1.12 & 1.10 & 1.92 & 0.86 & 0.25 & 0.72 & 0.90 \\
\hline 2100 & 0.64 & 1.06 & 0.35 & 1.67 & 2.39 & 1.86 & 1.80 & 3.39 & 1.40 & 0.48 & 1.29 & 1.54 \\
\hline $\begin{array}{l}\text { Notes: Ben } \\
2010 \text { and } \\
\text { contains } 12 \\
\text { India (IND } \\
\text { countries ( } \\
\text { real interes }\end{array}$ & $\begin{array}{l}\text { efits and } \\
\text { ICE mo } \\
\text { regions } \\
\text {, Latin }\end{array}$ & $\begin{array}{l}\text { costs } \\
\text { del run } \\
\text { : China } \\
\text { Americ } \\
\text { her. Be } \\
\text { RICF }\end{array}$ & $\begin{array}{l}\text { differ } \\
\text { Lailabl } \\
\text { CHI), I } \\
\text { LatA), }\end{array}$ & $\begin{array}{l}\text { aces be } \\
\text { at http } \\
\text { hited } \mathrm{St} \\
\text { frica ( }\end{array}$ & $\begin{array}{l}\text { veen } \\
\text { /norc }\end{array}$ & $\begin{array}{l}\text { scen } \\
\text { Is.eco } \\
\text {, Rus } \\
\text { ddle I }\end{array}$ & $\begin{array}{l}\text { os } \mathrm{Opt} \\
\text { ale.ed } \\
\text { (RUS) } \\
\text { (Mid) }\end{array}$ & $\begin{array}{l}\text { Ral a } \\
\text { RIC } \\
\text { Japa } \\
\text {, Eu }\end{array}$ & $\begin{array}{l}\text { Basel } \\
\text { odels } \\
\text { JPN), } \\
\text { ia (Eu }\end{array}$ & $\begin{array}{l}\text { in } \mathrm{R} \\
\mathrm{n}) . \mathrm{Tl} \\
\text { Iropec } \\
\text {, Oth }\end{array}$ & $\begin{array}{l}\text { E (No } \\
\text { RICE } \\
\text { Unior } \\
\text { high i }\end{array}$ & $\begin{array}{l}\text { auus } \\
\text { odel } \\
\text { aU), } \\
\text { ome } \\
\text { onal }\end{array}$ \\
\hline
\end{tabular}




\subsection{Evaluation}

The main question of the paper is, whether inequality aversion is able to improve the incentives to cooperate in international climate policy. We can answer this question by using our estimates from Sections 3.1 and 3.2 in order to evaluate whether (9) and (10) hold empirically. Note that the payoff hierarchy within the public good game is determined endogenously. This is due to the fact that it depends on two determinants, the initial endowment on the one hand and the amount contributed to the public good on the other hand. Thus, we cannot rule out that the ex-ante position of a country (determined solely by the given initial endowments) may change due to the contribution decision. But this implies that there is a huge number of possible payoff hierarchies that would principally have to be considered. We abbreviate the analysis by taking only the best case scenario into account, i.e. the constellation of parameters that makes the RHS of (9) or (10) achieve their minimum values. Obviously, this is the case when the country under consideration ranks highest in the payoff hierarchy (i.e. $h=0$ ).

Table 3: Critical Values and Benefits

\begin{tabular}{|c|c|c|c|c|c|c|c|c|c|c|c|c|}
\hline \multirow[b]{2}{*}{ through } & \multicolumn{2}{|c|}{$\mathrm{CHI}$} & \multicolumn{2}{|c|}{ US } & \multicolumn{2}{|c|}{ RUS } & \multicolumn{2}{|c|}{ JPN } & \multicolumn{2}{|c|}{ EU } & \multicolumn{2}{|c|}{ IND } \\
\hline & $a_{j} g^{\prime}$ & $b_{j}^{c r i t}$ & $a_{j} g^{\prime}$ & $b_{j}^{c r i t}$ & $a_{j} g^{\prime}$ & $b_{j}^{c r i t}$ & $a_{j} g^{\prime}$ & $b_{j}^{c r i t}$ & $a_{j} g^{\prime}$ & $b_{j}^{c r i t}$ & $a_{j} g^{\prime}$ & $b_{j}^{c r i t}$ \\
\hline 2055 & 95.1 & 279.1 & 90.1 & 125.3 & 8.9 & 17.2 & 21.4 & -3.9 & 101.4 & 63.4 & 93.6 & 74.5 \\
\hline \multirow[t]{2}{*}{2100} & 370.4 & 489.3 & 308.2 & 256.3 & 28.4 & -21.7 & 64.3 & -0.7 & 340.3 & 107.0 & 370.0 & 163.7 \\
\hline & \multicolumn{2}{|c|}{ LatA } & \multicolumn{2}{|c|}{ AFR } & \multicolumn{2}{|c|}{ MidE } & \multicolumn{2}{|c|}{ EurA } & \multicolumn{2}{|c|}{$\mathrm{OHI}$} & \multicolumn{2}{|c|}{ Other } \\
\hline through & $a_{j} g^{\prime}$ & $b_{j}^{c r i t}$ & $a_{j} g^{\prime}$ & $b_{j}^{c r i t}$ & $a_{j} g^{\prime}$ & $b_{j}^{c r i t}$ & $a_{j} g^{\prime}$ & $b_{j}^{c r i t}$ & $a_{j} g^{\prime}$ & $b_{j}^{c r i t}$ & $a_{j} g^{\prime}$ & $b_{j}^{c r i t}$ \\
\hline 2055 & 57.4 & 42.6 & 68.9 & 26.4 & 82.6 & 71.7 & 7.0 & 1.2 & 32.0 & $\overline{19.0}$ & 72.0 & 56.0 \\
\hline 2100 & 215.9 & 82.9 & 337.9 & 64.3 & 316.8 & 190.2 & 26.9 & -47.0 & 106.2 & 43.6 & 328.4 & 177.3 \\
\hline
\end{tabular}

Notes: Benefits, $a_{j} g^{\prime}$, and critical values, $b_{j}^{\text {crit }}$, according to (9) or (10) under the best case scenario $(h=0)$. Used values for F\&S parameters are $\alpha_{[0.5]}=0.833$ and $\beta_{[0.5]}=0.288(\mathrm{~F} \& \mathrm{~S} 1999)$.

As an example, the critical value for China in 2055, $b_{C H I}^{\text {crit }}$, is (according to (9)) computed as follows:

$b_{C H I}^{c r i t}=p_{C H I}-\frac{0.288\left(a_{U S} g^{\prime}+a_{R U S} g^{\prime}+\ldots+a_{\text {Other }} g^{\prime}\right)}{11(1-0.288)}=302.5-\frac{0.288(90.1+8.9+\ldots+72.0)}{7.832}=279.1$.

Table 3 shows the critical values and the marginal benefits for the time horizons until 2055 and 2100 using the median values from F\&S' distribution of inequality aversion parameters. Consider first the time horizon until 2055. As we can clearly see, the empirically estimated marginal benefits do not exceed the critical values for important countries in climate negotiations. For China, the US and Russia, the critical condition (9) for contributing to the 
public good climate protection is violated. Remember that this result has been obtained under best case assumptions, i.e. the country under consideration ranks on top of the global payoff hierarchy. Hence, the difference between $a_{j} g^{\prime}$ and $b_{j}^{\text {crit }}$ would be even bigger for countries like China or Russia when more realistic positions in the payoff order are considered. On the other hand, benefits of regions such as the EU, Africa and Japan are high enough to offer incentives for climate protection. This result may partly explain why the EU has been particularly engaged in climate policy and pushed for international agreements so actively in the past.

Comparing the values without inequality aversion (Table 2) and with inequality aversion (Table 3), we find that for Japan, the Mid East, EurA, OHI and Other, inequality aversion has a positive impact on the incentives to contribute to the global public good climate protection. For all other countries, the initial decision with standard preferences remains the same if we take inequality aversion into account.

A brief look at the data for 2100 reveals that the prospects for cooperation in climate protection are much more favourable in this case. There is only one country, China, which has no incentives to contribute. In general, for all countries or regions, the necessary conditions for contributing are much less demanding. Note, however, that conditions (9) and (10) are only necessary conditions for contributing to climate protection. In order to investigate whether countries really would be willing to enter into an international agreement on climate mitigation, a more sophisticated analysis would be necessary, e.g. within a coalition formation framework. The public good model is well suited to demonstrate that regarding the time horizon until 2055, fundamental incentives for climate protection are very limited. But it also leaves open a number of important questions which certainly have an impact on a country's decision to contribute or not, e.g. the country's size or the composition of a climate coalition and burden sharing within such coalition.

\subsection{Sensitivity analysis}

We use the available estimates for F\&S parameters in order to prove the robustness of our results. Firstly, F\&S themselves present mean values for the assumed distribution in Table 1 $(\bar{\alpha}=0.85$ and $\bar{\beta}=0.315)$. Secondly, Blanco et al. (2011) use modified ultimatum and dictator games to obtain values for inequality aversion parameters. They present maximumlikelihood estimations of the parameters ( $\hat{\alpha}=0.91$ and $\hat{\beta}=0.38$ ). However, as Blanco et al. 
use student subjects $(N=61)$, the question of how far it is appropriate to apply these values to the context of international climate policy is well worth asking. Thirdly, Dannenberg at al. (2010) try to figure out empirical values for $\alpha_{j}$ and $\beta_{j}$ by asking participants $(N=155)$ of the international climate talks. For this purpose, they conducted an online experiment with individuals who had been involved in international climate policy. The experiment consisted of two simple non-strategic games resembling the ultimatum and dictator games, suited to measure individual inequality aversion as captured in the model by F\&S.7 They find that participants, on average, show a considerable aversion to advantageous inequality, while the aversion to disadvantageous inequality is moderate. The obtained mean values are $\bar{\alpha}=0.394$ and $\bar{\beta}=0.561$. While the median for the weight of the disadvantageous inequality aversion strongly deviates from the mean $\left(\alpha_{[0.5]}=0\right)$, the median for the weight of the advantageous inequality aversion is rather similar to the mean $\left(\beta_{[0.5]}=0.53\right)$. Remarkably, the study cannot confirm significant differences with respect to geographical variety, i.e. negotiators from all regions of the world show rather similar degrees of inequality aversion. Moreover, Dannenberg et al. (2010) asked their participants to imagine that decisions in their experiment had to be made by members of a delegation of their country on a Conference of the Parties (COP) or in a meeting of the Subsidiary Bodies. By and large, respondents expected their country delegates to act in a more selfish way than themselves. This means that the values of $\alpha_{j}$ and $\beta_{j}$ obtained in this study can be regarded as upper bounds.

If we use the mean values from Table 1 (F\&S 1999), no changes with respect to the incentives to contribute can be observed (Scenario S1, Table 4 in the appendix). If we adopt the inequality aversion parameters obtained in Blanco et al. (2011), most of our results from Section 3.3 remain robust. As Table 4 (Scenario S2) shows, based on a best case analysis we still can conclude that China and the US have no incentives to contribute to climate protection. Table 4 (Scenarios S3 and S4) also shows the results if we adopt aversion parameter values from Dannenberg et al. (2010). We still can safely conclude that China has definitely no incentive to participate in international climate agreements. For other countries, it is not possible to draw safe conclusions based on a best case scenario.

\footnotetext{
${ }^{7}$ In the modified ultimatum game used by Blanco et al. (2011), each subject reacts to an actual proposal of his or her co-player, i.e. there is a distinct element of strategic interaction in this game. In the modified ultimatum game used by Dannenberg et al. (2010), however, there is no direct interaction between both subjects and no room for strategic considerations. As the individual inequality aversion is estimated without strategic interaction between players, it is not surprising that the median value for $\alpha$ is very low and the corresponding mean value is strongly influenced by some outliers on the right tail of the distribution. Thus, one might be skeptical whether the $\alpha$ values of Dannenberg et al. (2010) are a correct measure of the aversion to disadvantageous inequality.
} 
Note, however, that Dannenberg et al. (2010) obtained an exceptionally high value for $\beta$. Remember the notion of this parameter: If, e.g., $\beta=0.5$ in a two-player case, then a player would be indifferent between keeping one dollar of income for himself or giving the dollar away. We can hardly imagine that $\beta>0.5$ characterises the behaviour of countries engaged in climate policy. Perhaps the study suffers from a self-selection bias, and strongly equityoriented negotiators are overrepresented in their sample. Moreover, the obtained value for $\alpha$ is exceptionally low, and, particularly, the study finds $\beta>\alpha$. The bulk of empirical evidence, however, suggests that people suffer more from disadvantageous than from advantageous inequality (Loewenstein et al. 1989).

\section{Conclusion}

In this paper, we elaborated on the idea that the behaviour of countries in international environmental policy may be motivated by considerations of inequality aversion. We extended the model of inequality aversion introduced by F\&S to a context where players may differ with respect to their benefits and costs from contributing to a global non-linear public good climate protection. Hence, our model captures all essential real world dimensions of heterogeneity in the field of international climate policy: Countries obviously differ with respect to their economic wealth and to their expected damages from climate change and their abatement costs. We show that a country can only be expected to contribute to the global public good climate protection if its benefit is high enough. We evaluate this condition empirically by taking estimates for benefits and costs from the impact assessment model RICE and inequality aversion parameters from the experimental economics literature. We show that empirically, the critical condition for contributing fails to hold for major players in international climate policy except the EU and Japan. Our results are quite robust with respect to variations of the degree of inequality aversion. Even with extreme values, at least China, the world's biggest $\mathrm{CO}_{2}$ emitter, never contributes. Hence, although inequality aversion is a theoretically appealing way to solve the cooperation problem in social dilemmas, we should be careful not to overestimate its potential for solving real world negotiation problems in climate policy.

Finally, we would like to discuss briefly which policy lessons might be learned from this paper. From the viewpoint of international climate policy, the question of how voluntary cooperation in climate protection can be achieved still remains. Our model suggests that a country's benefit plays a crucial role compared to all other parameters, particularly the 
degrees of inequality aversion. Hence, an accurate measurement of a country's benefits and costs from climate policy is a prerequisite for the country to make a rational decision. Hence, it is highly important that governments are well-informed about the expected damages facing their country. The views on this topic are heavily influenced by the progress in climate-related research. A better understanding of the climate system, its changes and its impact on societies as well as adaptation options may alter the views on damages. For example, if new insights from science suggest that the probability for catastrophic climatic events is increasing, this may change the benefit-cost ratio and, hence, also influence a country's contribution decision in the public good game. On the other hand, if e.g. the abatement costs decrease due to technical progress, this may also change a country's decision to contribute or not to climate protection. Hence, it might be worthwhile to think about appropriate research policies to promote technical progress which would make emissions reductions cheaper.

There is a third less obvious determinant of the benefits. When calculating future climate damages, economists typically discount future values. Taking into account that the damages of an unmitigated climate change are significant in the remote future, the choice of the discount factor crucially affects the benefit: The higher the discount factor, the lower the expected damages and, thus, the lower the corresponding benefits from climate policy. Although economists widely agree with Nordhaus' (2008) view that discount factors are appropriate which are consistent with the returns on real world capital markets, the choice of the discount rate is not a purely scientific problem but involves a normative decision. This may give some leeway for the benefit-cost ratio due to ethical reasoning. ${ }^{8}$ Furthermore, there are strong arguments for choosing a discount rate near the very lowest expected rate of return in the long run (Weitzman 1999). Future research would have to improve our knowledge about the determinants of the benefit-cost ratio of climate policy and the corresponding effects on the contributions to the global public good climate protection.

\footnotetext{
${ }^{8}$ It would be an easy task to calculate discount rates necessary for making contributing worthwhile in our model.
} 


\section{References}

Barrett, S. (2005), Environment and Statecraft. The Strategy of Environmental Treaty-Making, Oxford.

Blanco, M., D. Engelmann, and H.-T. Normann (2011), A within Subject Analysis of Other-Regarding Preferences, Games and Economic Behavior 72, 321-338.

Bolton, G.E. and A. Ockenfels (2000), ERC - A Theory of Equity, Reciprocity and Competition, American Economic Review 90, 166-193.

Dannenberg, A., B. Sturm and C. Vogt (2010), Do Equity Preferences Matter for Climate Negotiators? An Experimental Investigation, Environmental and Resource Economics 47, 91-109.

Engel, G. (2010), Dictator Games: A Meta Study, Discussion Paper, Preprints of the Max Planck Institute for Research on Collective Goods 2010/07, Bonn.

Fehr, E. and K.M. Schmidt (1999), A Theory of Fairness, Competition, and Cooperation, Quarterly Journal of Economics 114, 817-868.

Fischbacher, U. and S. Gächter (2010), Social Preferences, Beliefs and the Dynamics of Free Riding in Public Good Experiments, American Economic Review 100, 541-556.

Güth, W., R. Schmittberger and B. Schwarze (1982), An Experimental Analysis of Ultimatum Bargaining, Journal of Economic Behavior and Organization 3, 367-388.

Kahneman, D., J.L. Knetsch and R.H. Thaler (1986), Fairness and the Assumptions of Economics, Journal of Business 59, 285-300.

Lange, A., A. Löschel, C. Vogt and A. Ziegler (2010), On the self-interested use of equity in international climate negotiations, European Economic Review 54, 359-375.

Lange, A., Vogt, C. and A. Ziegler (2007), On the importance of equity in international climate policy: an empirical analysis, Energy Economics 29, 545-562.

Lange, A. (2006), The impact of equity-preferences on the stability of heterogeneous international agreements, Environmental and Resource Economics 34, 247-267.

Lange, A. and C. Vogt (2003), Cooperation in International Environmental Negotiations due to a Preference for Equity, Journal of Public Economics 87, 2049-2067.

Loewenstein, G.F., L. Thompson and M. H. Bazerman (1989), Social Utility and Decision Making in Interpersonal Contexts, Journal of Personality and Social Psychology 57, 426-441.

Nordhaus, W.D. (2008), A Question of Balance: Economic Modeling of Global Warming, Yale.

Nordhaus, W.D. (2010), Economic aspects of global warming in a post-Copenhagen environment, Proceedings of the National Academy of Sciences 107, 11721-11726.

Oosterbeek, H., R. Sloof and G. van de Kuilen (2004), Cultural differences in ultimatum game experiments: Evidence from a meta-analysis, Experimental Economics 7, 171-188.

Posner, E.A. and D. Weisbach (2010), Climate Change Justice, Princeton.

Roth, A.E. (1995), Bargaining Experiments, in: Kagel, J.H. and A.E. Roth (Eds.), Handbook of Experimental Economics, Princeton.

Weitzman, M.L. (1998), Why the Far-Distant Future Should Be Discounted at Its Lowest Possible Rate, Journal of Environmental Economics and Management 36, 201-208. 


\section{Appendix}

Table 4: Critical Values and Benefits - Sensitivity Analysis

\begin{tabular}{|c|c|c|c|c|c|c|c|c|c|c|}
\hline through & $\overline{a a_{j} g^{\prime}}$ & $b_{j}^{c r i t, S 1}$ & $b_{j}^{c r i t, S 2}$ & $b_{j}^{c r i t, S 3}$ & $b_{j}^{c r i t, S 4}$ & $a_{j} g^{\prime}$ & $b_{j}^{c r i t, S 1}$ & $b_{j}^{c r i t, S 2}$ & $b_{j}^{c r i t, S 3}$ & $b_{j}^{c r i t, S 4}$ \\
\hline & \multicolumn{5}{|c|}{$\mathrm{CHI}$} & \multicolumn{5}{|c|}{ US } \\
\hline 2055 & 95.1 & 275.9 & 267.1 & 237.3 & 228.7 & 90.1 & 122.1 & 113.2 & 83.24 & 74.5 \\
\hline \multirow[t]{2}{*}{2100} & 370.4 & 476.8 & 442.8 & 328.4 & 295.0 & 308.3 & 253.3 & 246.7 & 171.3 & 200.4 \\
\hline & \multicolumn{5}{|c|}{ RUS } & \multicolumn{5}{|c|}{ JPN } \\
\hline 2055 & 8.9 & 13.6 & 3.5 & -30.2 & -40.1 & 21.4 & -7.4 & -17.3 & -50.5 & -60.2 \\
\hline \multirow{2}{*}{2100} & 28.4 & -35.7 & -74.5 & -204.8 & -242.9 & 64.3 & -3.9 & -11.1 & -93.9 & -62.0 \\
\hline & \multicolumn{5}{|c|}{ EU } & \multicolumn{5}{|c|}{ IND } \\
\hline 2055 & 101.4 & 62.6 & 61.0 & 42.1 & 49.4 & 93.6 & 73.8 & 72.1 & 53.0 & 60.3 \\
\hline \multirow[t]{2}{*}{2100} & 340.3 & 104.0 & 97.6 & 23.1 & 51.8 & 370.0 & 160.7 & 154.4 & 80.8 & 109.2 \\
\hline & \multicolumn{5}{|c|}{ LatA } & \multicolumn{5}{|c|}{ AFR } \\
\hline 2055 & 57.4 & 41.8 & 40.1 & 39.8 & 27.6 & 68.9 & 25.6 & 23.9 & 17.7 & 11.7 \\
\hline \multirow[t]{2}{*}{2100} & 215.9 & 79.8 & 73.0 & -5.2 & 24.9 & 337.9 & 61.3 & 54.9 & -19.7 & 9.1 \\
\hline & \multicolumn{5}{|c|}{ MidE } & \multicolumn{5}{|c|}{ EurA } \\
\hline 2055 & 82.6 & 68.5 & 59.5 & 29.1 & 20.3 & 7.0 & -2.4 & -12.5 & -46.4 & -56.2 \\
\hline \multirow[t]{2}{*}{2100} & 316.8 & 187.2 & 180.7 & 105.5 & 134.5 & 26.9 & -61.0 & -99.8 & -230.2 & -268.2 \\
\hline & \multicolumn{5}{|c|}{$\mathrm{OHI}$} & \multicolumn{5}{|c|}{ Other } \\
\hline 2055 & 32.0 & 15.5 & 5.8 & -26.9 & -36.5 & 72.0 & 52.7 & 68.3 & 12.7 & 3.7 \\
\hline 2100 & 106.2 & 40.4 & 33.3 & -48.2 & -16.8 & 328.4 & 174.3 & 167.9 & 93.1 & 121.9 \\
\hline
\end{tabular}

Notes:

Benefits, $a_{j} g^{\prime}$, and critical values, $b_{j}^{\text {crit }}$, according to (9) or (10) under the best case scenario $(h=0)$. Scenario S1: Values used for F\&S parameters are $\bar{\alpha}=0.85$ and $\bar{\beta}=0.315$ (F\&S 1999). S2: Values used for $\mathrm{F} \& S$ parameters are $\hat{\alpha}=0.91$ and $\hat{\beta}=0.38$ (Blanco et al. forthcoming). S3: Values used for F\&S parameters are $\alpha_{[0.5]}=0$ and $\beta_{[0.5]}=0.53$ (Dannenberg et al. 2010). S4: Values used for F\&S parameters are $\bar{\alpha}=0.394$ and $\bar{\beta}=0.561$ (Dannenberg et al. 2010). 